\title{
FIBER FABRIC AS AN ELEMENT OF SIGNAL SYSTEMS
}

\author{
P. Vankevych, V. Dehtyarenko, B. Drobenko, Yu. Nastyshyn
}

The article presents research materials for developing fiber-optic sensors that can be integrated into items of clothing or combat equipment of servicemen. The geometric, mechanical and functional characteristics of the sensors can be varied depending on the purpose of the signal element, which allows their integration into textile materials, which are the basis for the manufacture of military equipment. Replacement of areas of textile fabric in places where it covers the optical sensor with fabric elements made of optical fibers has a multifunctional purpose. First, due to its tissue structure, it expands the probing light beam from a spot (with a spatial dimension of $0 D$ ) into a $2 D$ scan, thereby improving the spatial sensitivity diagram of the sensor. Second, it replaces the removed tissue on top of the sensor, thereby restoring the integrity of the tissue. Third, it performs a protective and masking function for the sensor. In terms of strength, elasticity and durability, such fabric materials are almost indistinguishable from traditional ones. The paper experimentally demonstrates that the system of quasi-parallel fibers, which can be part of the fabric elements of clothing or equipment of a serviceman, plays the role of a diffraction grating for a laser beam. The shape of the diffraction band strongly depends on the angle of incidence of the light beam relative to the normal to the grating. The shape of the diffraction band is linear if the incident ray is in a plane perpendicular to the plane of the system of quasi-parallel optical fibers and at the same time perpendicular to the direction of the fibers. If the incident ray is outside this plane, then in the general case, the shape of the diffraction band is described by a second-order curve. The effect of curvature of the diffraction band when the laser beam falls obliquely on the lattice is a consequence of the so-called conical diffraction of light, in which the diffracted rays propagate along the surface of the cone. In particular, if the incident ray is in a plane perpendicular to the plane of the fiber system (grating) and parallel to the direction of the fibers, then depending on the angle between the incident ray and perpendicular to the grating plane, the diffraction band is a hyperbola at angles of incidence smaller than $45^{\circ}$, parabola, when the angle of incidence is $45^{\circ}$ or ellipse at angles of incidence larger than $45^{\circ}$. The case of small angles of incidence when the diffraction band is a hyperbola is demonstrated in the work. The property of changing the type of the second-order curve (hyperbola / parabola / ellipse) of the diffraction band and its orientation (curved to the right / left or up / down) when changing the angle of incidence of the light beam on the grating can be used to determine the position of the light source (laser sniper sight) with respect to the fiber optic grating integrated into the item of clothing or equipment of the serviceman.

Key words: textile, fiber optical sensors, sensitive polymer materials, light wave, sound ray, light galo, diffractional maximum, diffraction equations, direction cosine, of cone conical cut, the curves of second rang.

UDK 621.396.96

DOI: https://doi.org/10.33577/2312-4458.23.2020.74-78

Ю.М. Косовцов, А.А. Звонко, В.В. Атаманюк, О.М. Дробан

Національна академія сухопутних військ, Львів

\section{МОЖЛИВОСТІ ЗМІНИ ДІАГРАМИ ЗВОРОТНОГО РОЗСІЮВАННЯ ОБ'ЄКТА, ПОВЕРХНЯ ЯКОГО УТВОРЕНА ПЛОСКИМИ ГРАНЯМИ, ШЛЯХОМ НАНЕСЕННЯ ФАЗОЗМІНЮЮЧОГО ПОКРИТТЯ}

\begin{abstract}
Проведена очінка можливості зниження радіолокачійної помітності об 'єктів, поверхня яких утворена поєднанням плоских граней за рахунок нанесення фазозмінюючого покриття. Визначені переваги використання фазозмінюючого покриття у порівнянні з радіопоглинаючим. Отримані діаграми зворотного розсіювання прямокутної грані без покриття та з нанесеним покриттям. 3 отриманих результатів видно, шуо за рахунок використання фазозмінюючого покриття можна досягти бажаних змін характеристики діаграми зворотного розсіювання об 'єкта, поверхня якого утворена плоскими гранями.
\end{abstract}

Ключові слова: радіолокаційна помітність, плоска електропровідна грань, фазозмінююче покриття, поглинаюче покриття, діаграма зворотного розсіювання, радіолокаційна станція.

\section{Постановка проблеми та аналіз останніх досліджень і публікацій}

Аналіз попередніх досліджень показує, що на даний час найбільш поширеним та ефективним способом зменшення радіопомітності є формування геометричної форми об'єкта у такому вигляді, що концентрує відбиту енергію у вузькому діапазоні кутів з врахуванням статистичних закономірностей орієнтації об’єкта відносно радіолокаційної станції (РЛС) та нанесення на об'єкт різного роду поглинаючих матеріалів і фарб. 
Принцип роботи таких методів полягає у тому, що падаюча електромагнітна енергія перетворюється на інші види енергії в самому матеріалі, який має складну фізичну і хімічну структуру. При цьому спостерігаються такі явища, як поглинання, розсіювання та дифракція електромагнітних хвиль [3, 6-9].

Як відомо, діаграма зворотного розсіювання (ДЗР) об’єкта залежить від розподілу амплітуди і фази розсіяного ним сигналу у напрямку приймальної антени РЛС, який у свою чергу, залежить від тієї частини випроміненої електромагнітної енергії, яка потрапляє на об'єкт, його геометричної форми та електродинамічних характеристик матеріалу поверхні [1-5].

Відповідно, зміна розподілу амплітуд і фаз розсіюваних елементів об'єкта приводить до зміни характеристики діаграма зворотного розсіювання (ДЗР) без зміни геометричної форми самого об'єкта.

Для дослідження можливостей зміни характеристик ДЗР об'єкта, поверхня якого утворена плоскими гранями, у даній роботі виконана оцінка ефектів використання фазозмінюючого покриття, що нанесено за спеціальними функціональними залежностями.

Отже, основною метою роботи $є$ отримання ДЗР плоскої електропровідної поверхні з нанесеним на неї фазозмінюючого покриття та дослідження характеру їі зміни у порівнянні з їі аналогом, але без нанесення.

\section{Виклад основного матеріалу}

ДЗР плоскої електропровідної поверхні являє собою функцію виду $|\sin (x) / x|$ та має велике значення ЕПР при напрямі опромінювання (спостереження), який близький нормалі до площини поверхні [10]. У всіх інших напрямах іiі ЕПР відносно повільно спадає (рис. 1).

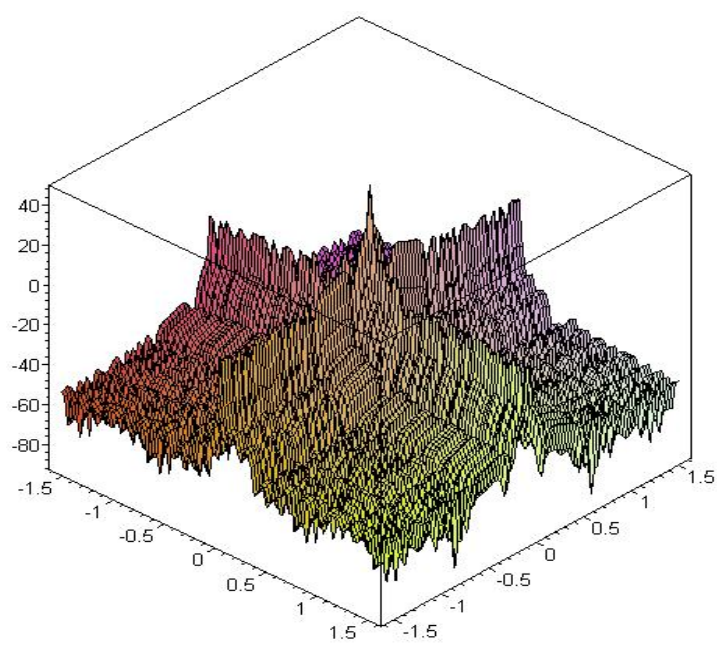

Рис. 1. ДЗР плоскої прямокутної грані
Корисного ефекту, $з$ точки зору зміни характеристики поведінки ДЗР такого об'єкта, можна досягти, збільшивши швидкість спадання ДЗР при відхиленні кута спостереження від нормалі, який можна отримати нанесенням поглинаючого матеріалу iз зміною його поглинаючих властивостей у відповідності з спеціально підібраною залежністю. Найпростіше реалізувати це пропорційною зміною товщини однорідного поглинаючого матеріалу, або використання багатошарового поглинаючого покриття, принцип дії якого показано на рис. 2.

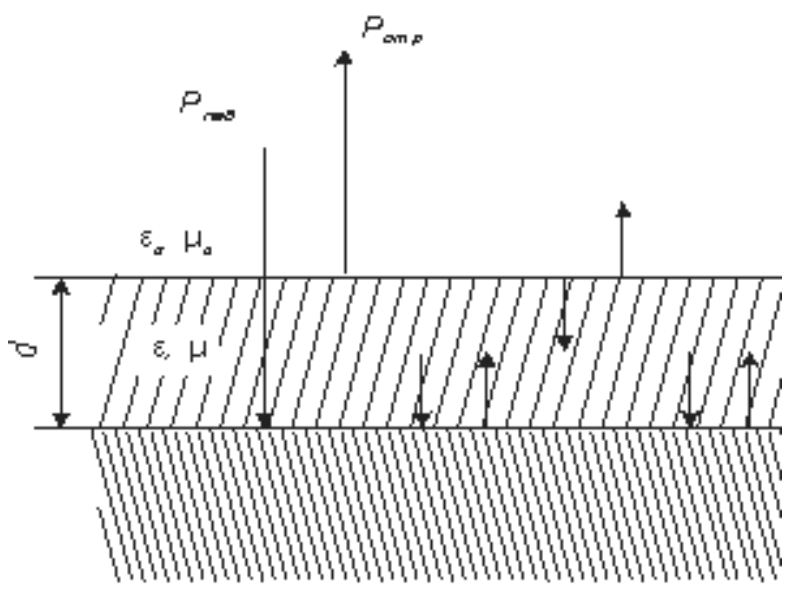

Puc. 2. Принцип дії поглинаючого покриття

3 рис. 2 видно, що для досягнення значних змін характеристики ДЗР необхідно суттєво збільшувати товщину шару поглинаючого матеріалу, що в свою чергу призведе до збільшення масогабаритних характеристик об'єкта. Рівномірне нанесення поглинаючого матеріалу призводить до зниження значення ефективної поверхні розсіювання у всьому діапазоні кутів опромінювання на величину, що залежить від товщини покриття.

Основною ідеєю даної роботи є використання фазозмінюючого покриття з метою дослідження можливості зміни ДЗР та визначення переваг та недоліків цього покриття у порівнянні з поглинаючими.

В даній роботі розглядається спрощена модель розсіювання плоскими поверхнями, на які нанесений однорідний фазозмінюючий матеріал. Дифракція описується методом фізичної оптики, а вплив матеріалу методом геометричної оптики. Аналізується однопозиційні ДЗР (кут опромінювання та спостереження співпадає).

Розглянемо декілька прикладів застосування описаного методу.

На рис. 3 наведені результати комп'ютерного моделювання ДЗР плоскої прямокутної грані 3 нанесеним на нього фазозмінюючим покриттям за законом «типу клин» 


$$
\Phi(\eta, \xi)=\eta a_{1}+\xi b_{1}+a_{0}
$$

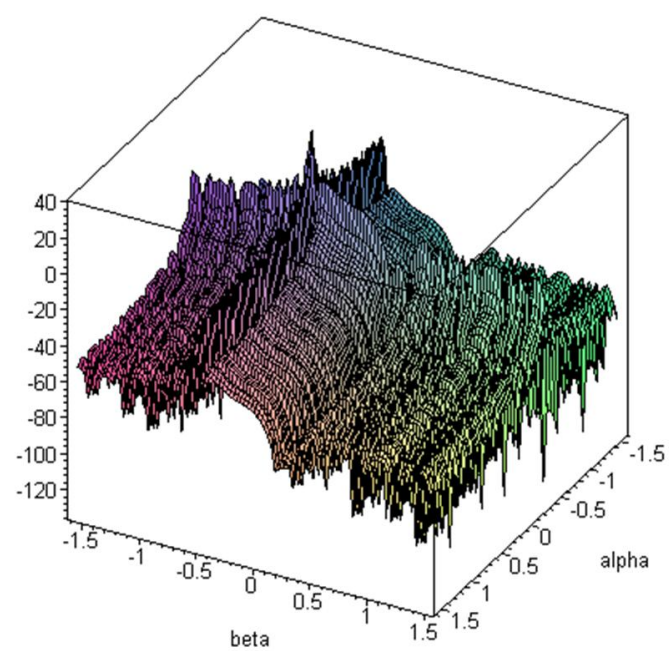

Рис. 3. ДЗР плоскої прямокутної грані, що отримана з використанням фазозмінюючого покриття за законом «типу клин»

Як було очікувано, ДЗР стає несиметричною, зміщуючись на деякий кут відносно нормалі до площини. Тобто таким чином можна змінювати положення максимуму ДЗР в потрібному напрямку.

На рис. 4 наведені результати комп'ютерного моделювання ДЗР плоскої прямокутної грані з нанесеним на неї фазозмінюючим покриттям за законом

$$
\Phi(\eta, \xi)=\left(a_{1}-\eta\right)^{2} b_{1}+\left(a_{2}-\xi\right)^{2} b_{2}
$$

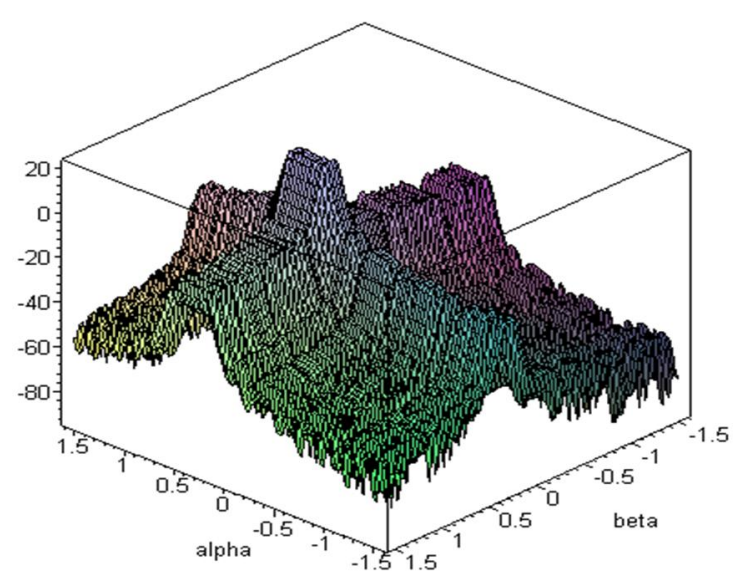

Рис. 4. ДЗР плоскої прямокутної грані, що отримана з використанням фазозмінюючого покриття за законом 2

3 рис. 4 видно, що в цьому випадку характер зміни ДЗР більш складний. Крім зміщення максимуму розсіювання спостерігається модифікація всієї діаграми та помітне ії згладжування.

Враховуючи, що можна використовувати велику кількість довільних законів нанесення фазозмінюючих покриттів запропонований метод дозволяе модифікувати ДЗР в будь-якому наперед відомому напрямку.

Враховуючи те, що в діапазоні кутів опромінювання від 0 до $30^{\circ}$ ДЗР плоскої грані, які отримані різними методами розрахунку розсіювання (фізична оптика, геометрична теорія дифракції, фізична теорія дифракції), практично не відрізняються між собою, можна зробити висновок, що використання фазозмінюючого покриття приводить до змін характеристик ДЗР плоскої прямокутної грані. Крім того це дає можливість визначити ряд переваг запропонованого методу у порівнянні з існуючими:

поглинаючі матеріали зменшують енергію розсіяного електромагнітного поля, фазозмінююче покриття - змінює напрямок поширення цієї енергії;

для зміни характеристики ДЗР не потрібно наносити велику кількість поглинаючого матеріалу, тобто відсутня залежність зміни характеристики від товщини нанесеного матеріалу.

\section{Висновки}

1. В роботі обгрунтована можливість зміни ДЗР об'єктів, поверхня яких утворена поєднанням плоских електропровідних граней, за рахунок нанесення на них фазозмінюючого покриття.

2. Проведені дослідження показують, що при нанесенні на плоску електропровідну поверхню фазозмінюючого покриття можливо досягти суттєвої зміни характеристики ДЗР.

3. Визначені переваги запропонованого методу у порівнянні з використанням поглинаючих покриттів.

\section{Список літератури}

1. Сидорчук О. Л. Аналіз методів і способів зменшення ефективної поверхні розсіювання антенних систем / О.Л. Сидорчук // ВІСНИК ЖДТУ. - 2012. - № 2 (61). C. 128-137.

2. Гончаренко Э. А. Снижение радиолокаиионной заметности военной техники и объектов / Э.А. Гончаренко.// Вологдинские чтения. - 2002. -№16. - С. 8-11.

3. Бєляєв Ю.Л. Радиопоглощающие материаль и технологии Стелс / Ю. Л. Бєляєв // Зарубежное военное обозрение. - 1993. - № 4. - С. 45-47.

4. Методи пасивного та активного гасіння ефективної площі иүілі / С. В. Ленков, М. І. Науменко, А. В. Головань [та ін.] // Збірник наукових праць Військового інституту Київського національного університету ім. Т. Шевченка. 2010. - № 27. - C. 171-177.

5. Атаманюк В. В. Дослідження діаграми зворотного розсіювання моделі головної частини ракети / В. В. Атаманюк, А. А. Звонко// Військово-технічний збірник. - 2014. № 10 . - C. 3-6.

6. Bhattacharyya A. K. Electromagnetic scattering from a flat plate with RIM loading and RAM saving RCS / A. K. Bhattacharyya // IEEE transactions on antennas and propagation. - 1989. - vol. 37. - № 5. - P. 659-663. 
7. Bhattacharyya A. K. Save radar absorbing material by coating only around the edges of a target for reduced RCS / A. K. Bhattacharyya // IEEE. - 1989. - vol. 38. - № 2. P. 856-859.

8. Antar Y. M. M. Effect of radar-absorbing materials on RCS of partially coated targets / Y. M. M. Antar, L. Hongwei // Microwave and optical technology letters. - 1998. - Vol. 17. № 5. - P. 281-284.

9. Рассеяние электромагнитных волн воздушными и наземными радиолокаиионными объектами: монография / О.И. Сухаревский, В.А. Василеи, С.В. Кукобко [и др.]; под ред. О.И. Сухаревского. - Харьков: ХУПС, 2009. - 468 с.

10. Кобак В. О. Радиолокационние отражатели. - М.: Советское радио, 1975. - 248 c.

\section{References}

1. Sudorchyk O.L. (2012), "Analiz metodiv i sposobiv zmenshennj efektuvnoi poverchni rozsiuvannj antennuh sustem" [Analysis of methods and ways of antenna system absolute cross-section minimization ] Military Technical Collection. Zhytomyr., 2012. Issue № 2. pp. 128-137. DOI: https:// doi.org/10.33577/2312-4458.21.2019.78-86 (Accessed 15 April 2020). [in Ukrainian].

2. Goncharenko E.A.(2002) "Snizenie radiolokacionnoi zametnosti voennoi techniki $i$ obektov [Reducing the radar signature of military equipment and objects] Vologda readings, 2002. Issue № 16. pp. 8-11. [in Russian].

3. Beljev U.L.(1993) "Radiopoglochauchue materialu $i$ technologii stealth" [Radar absorbing materials and technologies Stealth ] Foreign military review, 1993. Issue № 4. pp. 45-47. [in Russian].

4. Lenkov S.V., Naumenko M.I. Golovan A.B. (2010), "Metodu pasuvnogota aktuvnogo gasinnj efektuvnoi plochi cili" [Methods of passive and active quenching of the effective scattering area of the target]. VIKNU. Kyiv, 2010. Issue № 27. pp. 171-177. [in Ukrainian].

5. Atamanuk V. V., Zvonko A. A. (2014), "Doslidzennj diagram zvorotnjogo rozsiuvannj golovnoi chastunu raketu [Analysis of the backscattering pattern of the missile head]" Military Technical Collection. Lviv,. - 2014. - № 10. - P. 3-6. DOI https://doi.org/10.33577/2312-4458.10.2014.3-6. (Accessed 15 April 2020). [in Ukrainian].

6. Bhattacharyya A. K. (1989), "Electromagnetic scattering from a flat plate with RIM loading and RAM saving RCS" IEEE transactions on antennas and propagation. - 1989. vol. 37. - № 5. - P. 659-663. DOI: 10.1109/8.24195. (Accessed 15 April 2020). [in English].

7. Bhattacharyya A. K. (1989), " Save radar absorbing material by coating only around the edges of a target for reduced RCS " IEEE transactions on antennas and propagation. - 1989. - vol. 38. - № 2. - P. 856-859. DOI: 10.1109/APS.1989.134827 (Accessed 15 April 2020). [in English].

8. Antar Y. M. M., L. Hongwei (1998), " Effect of radarabsorbing materials on RCS of partially coated targets " Microwave and optical technology letters. - 1998. - vol. 17. № 5. - P. 281-284. DOI: https://doi.org/10.1002/(SICI)10982760(19980405)17:5<281::AID-MOP1>3.0.CO;2-8

(Accessed 15 April 2020). [in English].

9. Sukharevsky O.I., Vasilec V.A., Kykobko S.V. (2009) "Rassejnie elektromagnitnuch voln vozduchnumi I nazemnimi radiolokacionnimi objektami [Scattering of electromagnetic waves by air and ground radar objects]: Charkov, 468 p. [in Russian].

10. Kobak V.O. (1975), "Radiolokacionnue otrazateli" [Radar reflectors]: Moskva, 248 p. [in Russian].

\section{Возможности изменения диаграммы обратного рассеяния объекта, поверхность которого образована плоскими гранями, путем нанесения фазосдвигающего покрытия}

Ю.М. Косовцов, А.А. Звонко, В.В. Атаманюк, О.М. Дробан

Определено, что наиболее эффективный способ изменения диаграммы обратного рассеяния для уменьшения радио заметности объектов является формирование геометрической формы объекта в таком виде, что кониернтрирует отраженную энергию в узком диапазоне углов с учетом статистических закономерностей ориентации объекта относительно РЛС, и нанесение на объект разного рода поглощающих материалов и красок.

Описанный процесс уменьшения радиолокащионной заметности объектов путем использования поглощающих материалов и обоснованно, что увеличение толщины слоя поглощающего материала приводит к увеличению массогабаритных характеристик объекта, что не всегда возможно.

Показана возможность и проведена оиенка снижения радиолокационной заметности объектов, поверхность которых образована сочетанием плоских граней за счет нанесения фазосдвигающего покрытия. Полученные диаграммы обратного рассеяния прямоугольной грани без покрытия и с нанесенным покрытием.

Проведенный анализ и определены преимущества использования фазосдвигающего покрытия по сравнению с радиопоглощающим. Из полученных результатов видно, что за счет использования фазосдвигающего покрытия можно достичь изменений характеристики диаграммы обратного рассеяния объекта, поверхность которого образована плоскими гранями.

Показана возможность использования большого количества произвольных законов нанесения фазосдвигающих покрытий позволит модифицировать диаграммы обратного рассеяния в любом заранее известном направлении. Определены перспективы использования предложенного метода.

Ключевые слова: радиолокационная заметность, плоская электропроводящая грань, фазосдвигающее покрытие, поглощающее покрытие, диаграмма обратного рассеяния, радиолокационная станция. 


\title{
POSSIBILITIES OF CHANGING THE DIAGRAM OF REVERSE DISSIPATION OF AN OBJECT WHICH THE SURF ACE IS FORMED BY FLAT FACES BY APPLYING A PHASE CHANGE
}

\author{
Y. Kosovtsov, A. Zvonko, V. Atamanyuk, O. Droban
}

It is determined that the most effective way to change the backscatter diagram to reduce the radio visibility of objects is to form the geometric shape of the object in such a way that concentrates the reflected energy in a narrow range of angles, taking into account statistical patterns of orientation of the object of various absorbing materials and paints.

The process of reducing the radar visibility of objects by using absorbing materials is described and it is substantiated that increasing the thickness of the absorbing material layer leads to an increase in the mass and size characteristics of the object, which is not always possible.

The possibility and assessment of the reduction of radar visibility of objects, the surface of which is formed by a combination of flat faces due to the application of a phase-changing coating, is shown. The obtained backscattering diagrams of a rectangular face without coating and with coating.

The analysis is carried out and the advantages of using a phase-changing coating in comparison with a radioabsorbing one are determined.

The results show that by using a phase-shifting coating, it is possible to achieve changes in the characteristics of the backscattering diagram of an object whose surface is formed by flat faces.

The possibility of using a large number of arbitrary laws of application of phase-changing coatings is shown, which will allow modifying the backscattering diagrams in any previously known direction. The prospects of using the proposed method are determined.

Keywords: radar visibility, flat conductive face, phase-shifting coating, absorbing coating, backscattering diagram, radar station. 